\title{
Health Care Providers Knowledge as Correlates of their Attitudes Towards Leprosy Sufferers in Nigeria
}

\author{
Christian Ewhrudjakpor \\ Department of Sociology \& Psychology, Delta State University, P.M.B. 1 \\ Abraka, Nigeria \\ Cell Phone No: +2348035884715, E-mail: acadchris@yahoo.com
}

KEYWORDS Education; Hansen disease; hospital staff; stigmatization

\begin{abstract}
This study was conceived against the hunches of seemingly inadequate knowledge and blatant stigmatization of leprosy sufferers amongst health practitioners in Nigeria. It aimed at relating health workers knowledge and consequent attitude towards leprosy patients. Five hundred and eighty seven health workers comprising males and females drawn from government and private owned health care infrastructures participated in this study. A knowledge-Attitude structured questionnaire was used to measure the relationship between the respondent's knowledge and attitude variables towards leprosy patients. Results using simple percentages and the Statistical package for Social Science (SPSS) version 9, specifically the Pearson product moment correlation confirmed that health workers' above average knowledge of leprosy relates positively with attitudes towards leprosy patients $(\mathrm{r}=0.62$, d.f $=585 ;<.05$, two-tailed test $)$. The Researcher suggested that knowledge be further improved in order to sustain positive attitudes of health workers towards sufferers of leprosy.
\end{abstract}

\section{INTRODUCTION}

Seventy-five years after the first leprosy sufferer was medically treated (Awofeso, 1992) Nigerian medical practitioners (especially private medical practitioners) seem to know little and like less of attending to leprosy sufferers (Ajala, 1983; Onipede, 2000; Ogundipe, 2003) It is without qualms to believe that destigmatizing leprosy and its sufferers of the gigantic residual sociological and psychological problems they encounter daily in their interactions with non leprosy people needed the commitment of all especially the health care givers (Ewhrudjakpor, 2004). It is against this background that the Nigerian government in 1999 introduced the integration of leprosy control with the general primary health care services in the all embracing leprosy elimination campaign programmes (Ministry of Health, 1999).

Before the Nigerian government control of leprosy in 1930 with the establishment of Uzuakoli leprosy settlement, the socio-medico knowledge of the disease was scanty or non existent in most parts of Nigeria To large extent leprosy patients in Nigeria are assumed to be government responsibility hence only government health institutions personnel have the onerous responsibility to kick-start changing attitude towards leprosy patients. People can liken this to the rejection of lepers in the olden days, when it was assumed to be the responsibility of priests of old. The Holy Bible says volume about lepro- sy and lepers, their neglect and care by Priests. But the large expanse of Nigeria and her huge population of about 120 million have made the proliferation of private owned hospices inevitable. They are mostly located in areas not covered by government health infrastructure. The Nigerian situation fits well into the (Hart, 1975) 'Inverse-care law that:

"The availability of good medical care tends to vary inversely with the need for it in the population served. This inverse care law operates more completely where medical care is most exposed to market forces and less to where such exposure is reduced".

Put differently, governments in Nigeria build and equip hospices in cities whereas the villages are left with an ill-equipped primary health centres where majority of leprosy patients are detected, neglected and tabooed by their family members, and neighbours. Despite the government and non-governmental efforts in educating the health care providers about leprosy related matters, it is appalling to know that knowledge about leprosy among health care practitioners in Nigeria is still below average (Ministry of Health, 1999).

Thus, both in the training of medical doctors and other health workers in daily medical activity (Briden and Maguire, 2003) the major emphasis tends to be given to the medical diagnosis and treatment of acute illness, because the diagnostic approach is central to the practice of med- 
icine but the attitude conveyed by the behaviour of the health worker towards a patient is also very important in this context. The healthcare workers' negative attitude serves as blockade to the proper and holistic treatment of persons affected by the leprosy disease (Croft and Croft, 1999). This attitude too, serves to reinforce the harmful traditional beliefs about leprosy among the populace. Hospitals and clinics are the resorts for the sick, but for leprosy patients it's a no-go-area (Tekle-Haimanot et al., 1992) Besides societal stigmatization, medics often shy away from providing medical care for this group of patients totaling an estimated 200,000 in Nigeria.

Quite a number of studies (Tekle-Haimanot et al., 1992; Premkumar et al.,1994; Croft and Croft, 1999; Briden and Maguire, 2003; Ewhrudjakpor, 2004) have been carried out on the attitudes of health practitioners towards leprosy affected persons in Europe, Americas, Asia, and Eastern Mediterranean, but a few in Nigeria. The outcomes of such studies particularly those that aimed at ascertaining the health workers attitude towards leprosy affected persons have been equivocal.

It was expected that good knowledge of the disease would elicit positive attitude and then facilitate, prevent and encourage effective holistic medical care of the affected persons by medics. The Objective of this study is to assess the amount of socio-medical knowledge healthcare workers in Nigerian hospitals have about leprosy. This knowledge is significant in changing the potential negative attitudes of healthcare workers towards sufferers of leprosy, in order to build a robust health worker-patient relationship. By extension, this shall facilitate changing the traditional negative beliefs, stigma and attitude of family members and others in the society towards leprosy and its sufferers because medics especially physicians and nurses are held in high esteem in Nigeria. This study can also be a basis for the formulation of policy on healthcare providers and stigmatized diseases like leprosy, epilepsy, tuberculosis, etc. This shall re-orientate generally the attitudes and perceptions about these ailments in Nigeria.

\section{MATERIAL AND METHODS}

This study relates to health care providers in Nigeria. In this study, healthcare workers select- ed were 600 comprising 480 healthcare workers from private owned health facilities in the 6 geopolitical zones of the country and 120 healthcare providers from 6 States (Government owned) Leprosy Referral Centers. The choice of selecting these respondents from non Government and government hospitals was because of their distant and close working relationships respectively with leprosy patients and their influence in communities.

\section{Sampling Technique}

The probability sampling method was used to select the health workers. The sample is drawn in such a way that the probability of each member of the population being selected can be specified. This technique was employed because the study population is literate and widely dispersed all over the country.

\section{Research Instruments}

The structured questionnaires validated were used to gather data from health care providers, namely:

Section A: Knowledge questionnaire. This contained 7 factors related to knowledge about leprosy. The responses were weighted differently depending on the options, ranging from 8 to 0,2 to 0 . The total maximum knowledge score is 34 with an average of 27.

Section B: Attitude questionnaire. The technique of summated ratings (Likert 1932) was used to construct the attitude scale. The 22 questions were framed in simple and clear sentences. The questions included positive and negative aspects of the disease of leprosy. Thus 11 positive and II negative statements were assigned a scale value of 1,2,0,3,4 representing these options, which the respondents have to choose one, namely; "strongly disagree". "Undecided", "disagree", "undecided", "agree" and "strongly agree" respectively. The total maximum attitude score was 110 and the average positive attitude score was 66.

\section{Procedure for Data Collection}

The researcher selected 6 assistants from the 6 states selected: Delta, Abia, Kaduna, Osun, Borno and Zamfara from the 6 Geo-political zones in Nigeria. On the essence of the study and tech- 
niques to distribute and retrieve the questionnaires the researcher debriefed these assistants. The assistants then distributed the questionnaires using the ratio of 1:3:5 (doctors, nurses, and others) considering the population of the category of health workers. The assistants, did the distribution and retrieval of the 600 hundred questionnaires and submitted to the researcher, out of the 600 questionnaires distributed, 587 representing $97.8 \%$ were considered fit for analysis.

\section{RESULTS AND DISCUSSION}

Knowledge of leprosy by health workers represents the cognitive components (intelligence, beliefs and values) constructed (Likert, 1932) from the environment resulting from active manipulation of the culture of the community, because health workers are members of the community and must be socialized. They must acquire health skills, and techniques to mould their attitudes. This knowledge further gives coherence, direction and patterns attitude and subsequent behaviour. Also the acquisition of knowledge serve as providing ready made postures into which incoming practices about leprosy can be processed and acted upon. Attitude on the other hand is the emotional and conative component, favourable or unfavourable, pleasant or unpleasant predisposition of health care providers towards the disease of leprosy and its sufferers. It was assumed that the more they know about leprosy the more they like the patients (Ajala, 2003).

The present study reveals an above average basic knowledge and a relatively positive attitude towards sufferers of leprosy by most of the health care providers studied. Findings that increases our hope that the leprosy elimination campaign programmes in Nigeria are on course. This hope is founded on the analysis of the data that there is significant relationship between knowledge acquisition of leprosy by health workers and their attitudinal predisposition towards leprosy sufferers (Croft and Croft, 1999).

In assessing the relationship of knowledge factors against their consequent attitudinal postures of 587 respondents (see Table 1), the Pearson-product moment correlation was used. This is because it measures the degree as well as the direction of linear relationship between two variables. Each knowledge factor is then measured against the dependent variable Y (attitude). The inter-correlationship amongst these knowledge (7 factors) and attitude is expressly shown in table 11 . There are 3 rows in the table 11, while the first row gives the coefficient of correlation of the 7 knowledge factors $\left(\mathrm{x}_{1}, \mathrm{x}_{2}, \mathrm{x}_{3}, \mathrm{x}_{4}, \mathrm{x}_{5}, \mathrm{x}_{6}, \mathrm{x}_{7}\right)$ against attitude which is 1.00 or $100 \%$ the second row gives the significance level .000 which practically chosen as .05 significance level of the test and the third row gives the number of observations (587 respondent) considered in the analysis.

It is the breakdown of how each knowledge factor reached significance when subjected to the chosen .05 level of significance which is 0.230 in the statistical table translates to the rejection or acceptance of leprosy sufferers. That is any knowledge factor score greater than 0.230 does significantly relates to positive attitude. Meaning that the knowledge factor in question does facilitate health workers attitudes towards leprosy sufferers (Briden and Maguire, 2003).

Therefore, except the knowledge factor of response to family $(\mathrm{r}=.181)$, all other 6 factors reached significance (see Table 2). This is confirmed in the overall correlation analysis as summarized in table 3. One significant finding in this study, is that ethnic beliefs' reached significance, despite the supernatural, preternatural and mystic (see table 1) misgivings of Nigerians generally towards leprosy and its sufferers in their cultures. It goes to show the vibrancy of the leprosy campaigns against stigma and Pseudo rehabilitation programmes in the health sector of the country. This is reflected in the table II Pearson correlation $(\mathrm{r}=.497<\mathrm{p} .05$, two-tailed test). Table 3 confirmed what is shown as the relationship between these 7 factors and attitudes of the respondents. Put simply, the knowledge factors considered relates positively with attitudes held by the respondents about $62 \%$ (see Table 3 ) rating above the average of .05 or $50 \%$, meaning that, as knowledge improves $62 \%$ attitudes towards leprosy and its sufferers will be $62 \%$ better.

Earlier results corroborated the findings of this present study. In their study entitled: understanding the attitude of multidisciplinary teams working in leprosy centre they found that twothirds of the health workers possess 'minimum desirable interaction with their patients. Although the cross-analysis they made, showed that laboratory technicians had the highest positive attitude towards leprosy patients and doc- 
Table 1: Health workers knowledge and attitude scores about leprosy $(\mathrm{N}=587)$.

\begin{tabular}{|c|c|c|c|c|}
\hline \multirow[t]{2}{*}{ Information } & \multirow[b]{2}{*}{ No } & \multirow[b]{2}{*}{$\%$} & \multirow{2}{*}{$\frac{\text { Knowledge }}{\text { Scores }}$} & \multirow{2}{*}{$\begin{array}{r}\text { Attitude } \\
\text { Scores }\end{array}$} \\
\hline & & & & \\
\hline \multicolumn{5}{|l|}{ Sources of Information } \\
\hline Town crier & - & - & - & - \\
\hline Parents & - & - & - & - \\
\hline Children & - & - & - & - \\
\hline Neighbours & - & - & - & - \\
\hline Media (Radio/T.V./Papers) & 58 & 9.90 & 1871 & 1060 \\
\hline Co-staff & 95 & 16.20 & 656 & 1488 \\
\hline Posters & 29 & 4.90 & 64 & 586 \\
\hline Know of person suffering leprosy. & 04 & 0.70 & 11 & 120 \\
\hline Reading Books & 296 & 50.40 & 983 & 2040 \\
\hline Workshops/Seminars & 105 & 17.90 & 420 & 966 \\
\hline Never heard of leprosy. & - & - & - & - \\
\hline \multicolumn{5}{|l|}{ Causes of Leprosy } \\
\hline Germs & 354 & 60.31 & 1092 & 3036 \\
\hline Hereditary & 09 & 1.53 & 52 & 228 \\
\hline Insects & - & - & - & - \\
\hline Curse/punishment & 03 & 0.51 & 14 & 68 \\
\hline Immoral conduct & - & - & - & - \\
\hline Witches & 23 & 3.92 & 366 & 622 \\
\hline Marrying a leprosy patient & - & - & - & - \\
\hline Poverty & 198 & 33.73 & 688 & 1076 \\
\hline I don't know & - & - & - & - \\
\hline \multicolumn{5}{|l|}{ Signs and Symptoms } \\
\hline Anaesthetic & 241 & 41.10 & 865 & 2848 \\
\hline Hypopigmented patches in the body & 205 & 34.90 & 684 & 1606 \\
\hline Loss of sensation of hands and legs & 101 & 17.20 & 467 & 1064 \\
\hline Enlarged painful patches & 09 & 1.50 & 22 & 74 \\
\hline Enlarged ear lobes with & - & - & - & - \\
\hline Loss of eyebrows and shiny skin & 31 & 5.30 & 206 & 204 \\
\hline \multicolumn{5}{|l|}{ Consequences } \\
\hline Deformities & 317 & 54.00 & 1414 & 3676 \\
\hline Ulcers in hands and feet & 103 & 17.60 & 286 & 966 \\
\hline Chronic illness & - & - & - & - \\
\hline Anaesthetic Patches & - & - & - & - \\
\hline Throughout the body & 164 & 27.90 & 488 & 1944 \\
\hline No change & 03 & 0.50 & 24 & 68 \\
\hline \multicolumn{5}{|c|}{ Response to Family and Friends Contracting Leprosy. } \\
\hline Supportive & 64 & 10.90 & 184 & 964 \\
\hline Shun & 30 & 5.11 & 64 & 301 \\
\hline Prayers & 40 & 6.81 & 96 & 396 \\
\hline Multi Drug Therapy (MDT) & 371 & 63.20 & 1224 & 3266 \\
\hline Traditional Medicine & 82 & 13.97 & 364 & 1488 \\
\hline Do not Know & - & - & - & - \\
\hline \multicolumn{5}{|l|}{ Ethnic Beliefs } \\
\hline Outcast & 212 & 36.11 & 1008 & 2948 \\
\hline Normal III Health & 140 & 23.85 & 886 & 1146 \\
\hline Taboo & 101 & 17.21 & 212 & 344 \\
\hline Ostracized & 64 & 10.90 & 74 & 168 \\
\hline Witch/Wizard & 30 & 5.11 & 44 & 63 \\
\hline Evil doer & 40 & 6.81 & 36 & 24 \\
\hline \multicolumn{5}{|l|}{ Curability of Leprosy } \\
\hline Curable & 497 & 84.67 & 2016 & 3338 \\
\hline Incurable & 04 & 0.68 & 22 & 114 \\
\hline Do not Know & 86 & 14.65 & 630 & 442 \\
\hline
\end{tabular}

tors showed the highest stigma towards these patients. However it is pertinent to note that this study was done in a vertical programme in which only leprosy patients were treated unlike the present study that covers horizontal programmes where leprosy patients are treated along with other patients of varied diseases. One important relationship between that study and the present 
Table 2: Computer Application SPSS output showing the Pearson Product-Moment Correlation Analysis on the relationship between health workers knowledge factors of Leprosy and their Attitudes towards leprosy Patients.

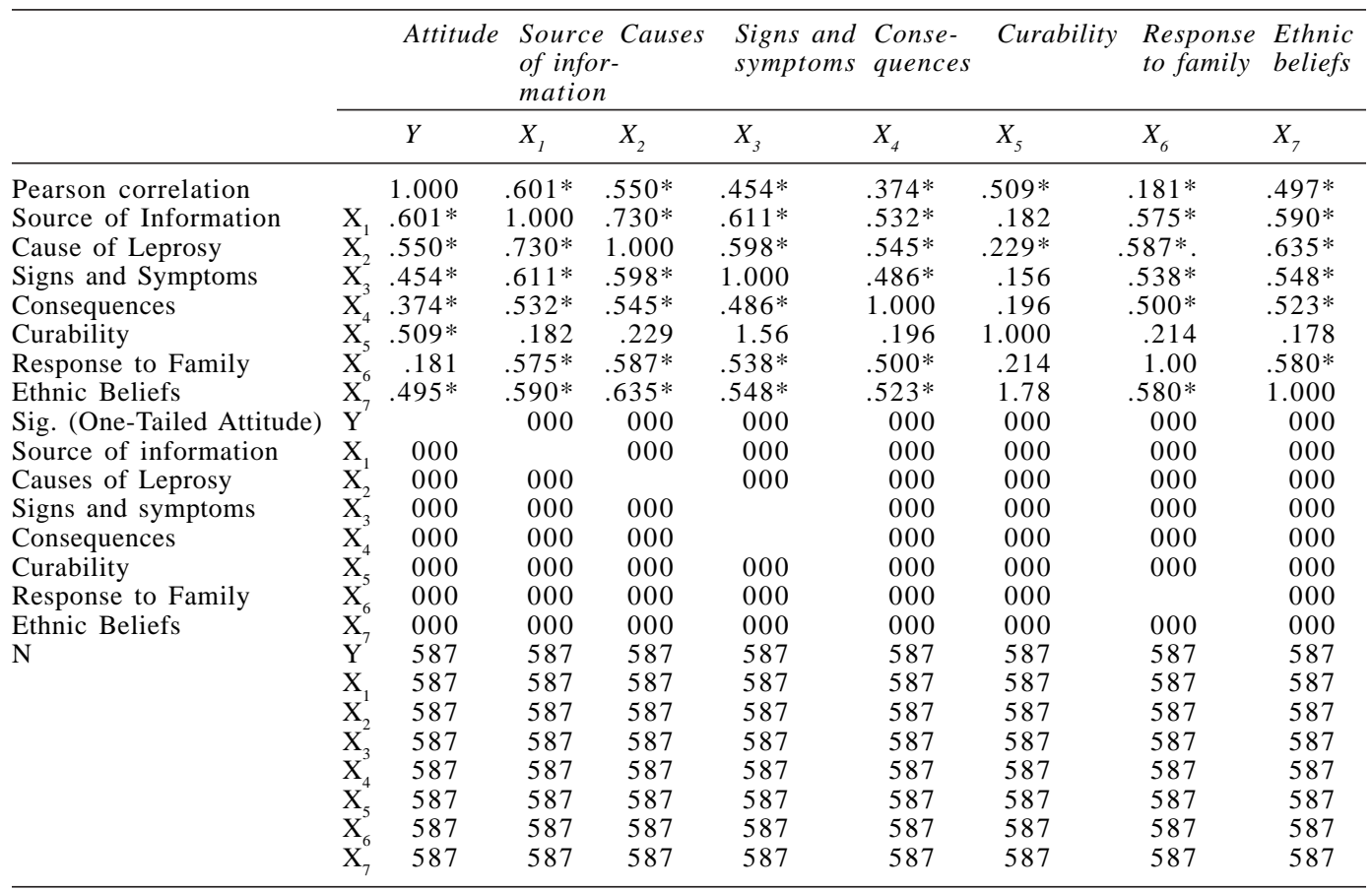

Table 3: Summary of Pearson Product-moment correlation showing the relationship between health workers total knowledge factors of Leprosy and their attitudes towards leprosy patients.

\begin{tabular}{lcccccc}
\hline Variables & Total score & Mean score & S.D. & d.f & r.obs & r.crit value 0.05 \\
\hline Knowledge of Leprosy N=587 & 15849 & 27.00 & 6.20 & 585 & 0.62 & 0.230 \\
Attitude towards leprosy patients $\mathrm{N}=587$ & 38742 & 66.00 & 9.30 & & & \\
\hline
\end{tabular}

research, is that both confirmed the hypothesis that health workers can care for leprosy patients (Ewhrudjakpor, 2004).

Also this finding supports the results of the studies (Croft and Croft, 1999) that knowledge relates positively with attitude, and health practices regarding leprosy in Bangladesh. Results here using chi-square and t-test showed high levels of knowledge and more favourable attitudes towards leprosy in areas that had reached intensive health education in contrast, there were very low levels of knowledge and unfavourable attitudes in areas that are difficult to reach with health education programmes. This is comparable with the Nigeria situation where most hightech' health infrastructures are located in cities while the rural areas where majority of the leprosy incidences occur have very few health facili- ties, where they exist they are poorly equipped with manpower and work materials, usually these are mainly Primary health centres referred to as (PHC). Anticipated by (Hart, 1975) this inverse proportion or mal distribution of health facilities in developing countries as creating disease palaces, detrimental to ameliorating the leprosy disease and its residual social problems. However (Awofeso, 1992; Ogundipe, 2003 ) reported an appraisal of the knowledge and attitudes of Nigerian nurses towards leprosy as having a below average basic knowledge and portraying negative attitudes toward leprosy patients. The difference in result between Awofeso, Ogundipe and the present study, apart from the method of analysis (simple percentages) used by Awofeso and Ogundipe which says little of attitude measurements, the time lag can explain great changes in 
leprosy elimination campaigns. The Period 2003 and 2005, 1992 and 2005 gives a difference of 2 years and 13 years which can make the significant difference as reported in the present study. This is further proof of the efficiency of the leprosy elimination campaign programmes embarked upon by the federal state governments and non-governmental organizations like British, Danish and German leprosy elimination campaign efforts (Ministry of Health, 1999).

To further assert the importance of improving knowledge and showing better attitudes towards leprosy in Nigeria the time lag effect in changing negative attitudes to positive attitudes towards sufferers of leprosy is also situated in the culture of the peoples of Nigeria. Now the semblance of this present study and others, assessed, is in the knowledge of care givers about leprosy patients, as reflected in the culture bound nature of leprosy as in most developing economies. Culture-the way of life of the people is a very powerful determinant of behaviour in these countries. In this present study the opinion of the researcher is that leprosy as a stigmatizing health condition needed to be effectively tackled through informed knowledge and the peoples transition as a result of meeting of cultures through the education of the population against the cultural beliefs among the peoples in nonindustrial societies (Premkumar et al.,1994). This is because health and disease are shaped by culture. Diseases like leprosy and behaviour patterns of the population are rooted in magic and religion, because most people (irrespective of their literacy level) in non-western societies like Nigeria attribute the incidence of leprosy to witchcraft, sorcery, and mystical forces (see Table 1) therefore their attitudinal predispositions is that of hatred, disdain, and neglect to the sufferers of this disease. The positive change of these beliefs is the strongest and finest outcome (see Tables 1 and 2) of the analysis of this research. Though sufferers are still tabooed, communities no longer quarantine them, though physicians and nurses still do not marry them, but they dine and wine together. These are indices to wholly accept leprosy sufferers as persons suffering from normal ill health in Nigeria (Onipede, 2000; Ewhrudjakpor, 2004).

\section{CONCLUSION}

Knowledge of health care providers significantly determines their attitudes towards sufferers of leprosy. Therefore it is recommended that governments and donor agencies should embark on measures to further improve knowledge of these care givers. This shall enable the sustainability of the empathetic postures by the care givers towards sufferers of leprosy.

\section{REFERENCES}

Ajala, B. 1983. "Elimination of Leprosy." The Guardian, June 16,1983 p. 22.

Awofeso, N. 1992. "Appraisal of the knowledge and Attitude of Nigerian Nurses toward leprosy." Leprosy Review, 63(92): 169-172.

Briden, A. and E. Maguire. 2003. "An Assessment of Knowledge and Attitudes towards Leprosy/Hansen's Disease Amongst Healthcare Workers in Guyana." Leprosy Review, 74(1): 154-162.

Croft, R.P. and R.A. Croft. 1999. "Knowledge, Attitude and Practice regarding Leprosy and Tuberculosis in Bangladesh." Leprosy Review, 70(1): 3442 .

Ewhrudjakpor, C. 2004. Knowledge and Attitude of Health Workers towards Leprosy Patients in Delta State. Ph.D Thesis (Unpublished)Abraka: Delta State University.

Hart, J.T. 1975. "The inverse care law." In: S. Cox and M. Mead (Eds.): A Sociology of Medical Practice. London: Collar Macmillian, pp. 97-98.

Likert, R. 1932. "A Technique for the measurement of Attitudes." Archives of Psychology. 140: 2-13.

Ministry of Health, 1999. A Three Year Development Plan for Leprosy Elimination 2000-2002. National Tuberculosis and Leprosy Control Programme. Abuja: Department of Primary Health Care and Disease Control.

Ogundipe, S. 2003. "Leprosy is less infectious than Envisaged." Vanguard, February 4, 2003 p.18.

Onipede, B.L. 2000. "A Chronic Disease." Concord, March 31, 2000 p.5.

Premkumar, K., S. Kumar and S.L. Dave. 1994. "Understanding the Attitude of Multidisciplinary Teams Working in Leprosy Toward their Patients." Leprosy Review, 65(1): 66-76.

Tekle-Haimanot, R.F., A. Gebre-Marian, L. Heijbe and R. Ekstedt. 1992. "Attitudes of Rural People in Central Ethiopia Towards Leprosy and Brief Comparison with Observations on Epilepsy." Leprosy Review, 63(2): 157-165.

The Holy Bible King James Version Numbers, 12:9-14, Leviticus, 13:1-5, II Kings, 5, Matthew 8:2, Luke $17: 12$. 